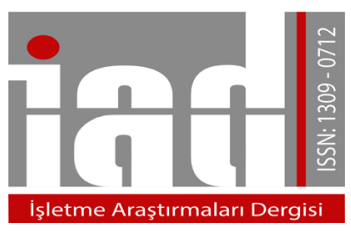

\author{
İşletme Araştırmaları Dergisi \\ Journal of Business Research-Turk \\ 10/4 (2018) 384-400
}

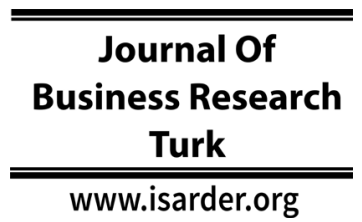

Araștırma Makalesi

\title{
Bir Gölge Bankacılık Uygulaması Olarak Gayrimenkul Finansmanında Alternatif Bir Faizsiz Finansman Modeli: İpoteğe Dayalı Paylaşımlı Faizsiz Finansman Modeli \\ An Alternative Non-Interest Real Estate Financing Model as a Shadow Banking Practice: Mortgage-backed Non-interest Shared Finance Model
}

\author{
Mustafa OKUR \\ Marmara Üniversitesi \\ Bankacılık ve Sigortacılık YO. Sermaye \\ Piyasası Bölümü, İstanbul Türkiye \\ orcid.org/0000-0003-3121-8603 \\ mustafaokur@marmara.edu.tr
}

\author{
Özgür ÇATIKKAŞ \\ Marmara Üniversitesi \\ Bankacılık ve Sigortacılık YO. Sigortacılık \\ Bölümü, İstanbul Türkiye \\ orcid.org/0000-0001-9547-8741 \\ ozgurcatikkas@marmara.edu.tr
}

\author{
Mehmet ERSOY \\ Marmara Üniversitesi \\ Bankacılık ve Sigortacılık YO. Sermaye Piyasası \\ Bölümü, İstanbul Türkiye \\ orcid.org/0000-0003-4057-6752 \\ mersoy@marmara.edu.tr \\ Özet
}

Konut finansmanı ülke ekonomisinin sürdürülebilir büyümesi için büyük önem taşımaktadır. Bu konu Türkiye gibi gelişmekte olan ekonomiler için daha da büyük önem taşımaktadır. Bu çalışmada Türkiye'de gayrimenkul finansmanında ve özellikle de konut finansmanında alternatif bir model olarak uygulanmakta olan tasarrufa dayalı faizsiz finansman modeli incelenmektedir. Bu açıdan bakıldığında mevcut uygulamanın bir gölge bankacılık uygulaması olduğu değerlendirilmektedir. Çalışmada ipoteğe dayalı paylaşımlı faizsiz finansman modeli olarak adlandırılan bu yöntem bankacılık sektöründeki düzenlemelerinin ve denetimlerin dişında kalmaktadır. $\mathrm{Bu}$ durum ülke ekonomisi açısından önemli bir potansiyel risk barındırmaktadır. Bu konuda düzenleyici otorite tarafindan acilen düzenleneme yapılmasına ihtiyaç vardır. Düzenlemeler özellikle lisanslama ve denetim konularında olmalıdır.

Anahtar Kelimeler: Konut Finansmanı, Tasarrufa Dayalı Faizsiz Finansman Modeli, Gölge Bankacılık

Gönderme Tarihi 30 Nisan 2018; Revizyon Tarihi 20 Kasım 2018; Kabul Tarihi 25 Kasım 2018

\section{Önerilen Atıf/ Suggested Citation:}

Okur, M., Çatıkkaş, Ö., Ersoy, M. (2018). Bir Gölge Bankacılık Uygulaması Olarak Gayrimenkul Finansmanında Alternatif Bir Faizsiz Finansman Modeli: İpoteğe Dayalı Paylaşımlı Faizsiz Finansman Modeli, İşletme Araştırmaları Dergisi, 10 (4), 384-400. 


\begin{abstract}
Housing finance is crucial for the sustainable growth of the country's economy. This issue is of even greater importance for emerging economies such as Turkey. In this study, especially residential real estate financing and financing interest-free financing model based on saving being implemented in Turkey is examined as an alternative model. From this point of view, the current implementation is considered to be a shadow banking application. This method, which is referred to as a mortgage-backed non-interest shared financing model in this study, is outside the regulations and controls in the banking sector. This situation poses a significant potential risk in terms of the country's economy. In this regard, regulatory authority is urgently required to make arrangements. Regulations should be in the areas of licensing and supervision in particular.
\end{abstract}

Keywords: Housing Finance, Mortgage-backed Non-interest Shared Housing Finance Model, Shadow Banking.

Received 30 April 2018; Received in revised from 20 November 2018; Accepted 25 November 2018

\title{
Giriş
}

Barınma problemi insanlığın tarihi kadar eski bir sorundur. Günümüzde ekonomik gelişmenin en önemli göstergelerinden biri bireylere sunulan konut imkânlarıdır. Yani gelişmiş bir ekonomide modern ve sağlam bir konutta yaşamak temel bir ihtiyaçtır. Gelişmiş bir ekonomi bireylere ihtiyaçları olan konutları sunmalıdır. Konut ihtiyacı ekonomik gelişme ve nüfus artışıyla birlikte artmaktadır. Bu yüzden gelişmekte olan ve nüfus artışı yaşayan ülkelerin karşılaştıkları en önemli sorunlardan birisi de konut problemidir. Ancak konut probleminin temelinde yalnızca nüfus artışı yatmamaktadır. Gelişmekte olan ülkelerde konut probleminin temelinde aslında konut finansmanı sorunu yatmaktadır. (Berberoğlu, 2005; Kömürlü, 2006)

Dünya geneline bakıldığında konut finansmanın bankalar, özel veya kamu konut finansman kuruluşları ve benzeri kuruluşlar gibi banka dışı kuruluşlar tarafından sağlandığ görülmektedir. Bu tip kuruluşlar tarafindan müşterilerine alternatif ürünler sunularak satın alınan konutların finansmanı sağlanmaktadır. Ancak genel olarak değerlendirildiğinde konvansiyonel finans sistemi tarafindan üretilen ve sunulan konut finansmanı ürünlerinin temeli faize dayanmaktadır. Ayrıca bazı gruplar özellikle de Müslümanlar inançları gereği faiz temelli konut finansman yöntemlerine mesafeli yaklaşmaktadırlar. Bu durum özellikle fonların yetersiz olduğu ve risk algısının yüksek olduğu gelişmekte olan ülkelerde konut finansman maliyetlerini yükseltmektedir. Dolayısıyla konut ihtiyacı olan bireylerin finansmana ulaşımını zorlaştırarak konut probleminin sürdürülebilir çözümünün önünde önemli bir engel oluşturmaktadır. 
Faiz temelli olan konvansiyonel sisteminin alternatifi olarak faizsiz finansman kuruluşları ve onların sundukları faizsiz ürünler değerlendirilebilir. Bu tip kuruluşlar finansman sağlamada faiz temelli araçlara alternatif olarak murabaha, muşaraka v.b. yöntemleri kullanmaktadır.(SERPAM, 2013) Ancak gerek uygulamadan kaynaklanan problemler, gerek toplumdaki bilgi eksikliği ve gerekse de sunulan alternatif ürünlerin yetersizliğinden dolayı faizsiz finansman sistemi de Türkiye'deki mevcut konut finansmanı ihtiyacını karşılayacak ciddi bir alternatif yaratamamaktadır.

İpoteğe dayalı paylaşımlı faizsiz finansman modeli (IP2FM) ${ }^{1}$ bireysel tasarruf ve ihtiyaçların finansmanı için günümüzde uygulaması da olan ciddi bir alternatif olarak karşımıza çıkmaktadır. Söz konusu yöntemin uygulanmasında katılımcılar organizatör firma tarafından çoğunlukla gruplar halinde organize edilmekte ve konut alımlarında finansman sağlanmaktadır. (Koç \& Çekin, 2017) Uygulamada çeşitli varyasyonları kullanılan bu yöntem alternatif bir konut finansmanı için çözümler sunmaktadır. Bu yöntem genel olarak organizatör firma olarak ifade edebileceğimiz firmalar tarafından uygulanmaktadır. Hâlihazırdaki uygulamalara teknik ve yasal düzenlemeler çerçevesinde bakıldığında ise, organizatör firmalar-aslında finansal aracılık hizmeti veriyorlar- finans sektörü düzenlemelerin kapsamı dışında kalmaktadırlar. Bundan dolayı mevcut uygulamaları bir gölge bankacılık uygulaması olarak kabul etmek mümkündür. (Claessens \& Ratnovski, 2015) Ancak bu sistemin sağliklı ve sürdürülebilir bir şekilde uygulanabilmesi ve yaşanan konut finansmanı sıkıntısına sağlıklı ve uzun vadeli bir çözüm olabilmesi için yasal altyapısının tarafların ve özellikle de kamunun zarar görmesini engelleyecek şekilde eksiksiz olarak oluşturulması gerekmektedir.

$\mathrm{Bu}$ çalışmanın ilerleyen bölümlerinde öncelikle gölge bankacılık tanımı ve dünyadaki yeri üzerinde durulacaktır. Sonraki bölümde ipoteğe dayalı paylaşımlı faizsiz finansman modeli (IP2FM) ve Türkiye'deki uygulamaları üzerinde durulacaktır. Devamında ise mevcut haliyle ipoteğe dayalı paylaşımlı faizsiz finansman modeli ile gölge bankacılık arasındaki ilişki değerlendirilecektir ve sonuç bölümünde ise konu ile ilgili olarak getirilen öneriler ve atılması gerekli adımlar tartışılacaktır.

\section{Gölge Bankacılık Kavramı ve Dünyadaki Mevcut Durum}

Uluslararası Finansal İstikrar Kurulu 2012 yılında yayınladığı raporda gölge bankacılık sistemini temel bankacılık hizmeti olan kredi fonksiyonunu yerine getiren

\footnotetext{
${ }^{1}$ Uygulamada farklı ve de eksik şekillerde adlandırılan faizsiz finansman yöntemi, bu çalışmada yazarlar tarafından “ipoteğe Dayalı Paylaşımlı Faizsiz Finansman Modeli” olarak ifade edilmiştir. Ayrıca kullanım kolaylığı açısından IP2FM kısaltması yazarlar tarafından İpoteğe Dayalı Paylaşımlı Faizsiz Finansman Finans Model'inin kısaltılması olarak kullanılmaktadır.
} 
ancak bankacılık sistemi düzenlemelerine tabi olmayan tüm teşekküller olarak tanımlamıştır.(Board \& Basel, 2015; Kodres, 2013) Bu sistemde kuruluşlar ticari bankaların sağladığı hizmetlere özellikle -mevduat toplama ve kredi verme gibi- benzer hizmetler sağlarken bankaların uymak zorunda oldukları düzenleme ve denetimlerin dışında kalmaktadırlar. Bu yapıyı açtığımızda sigorta şirketleri, faktöring şirketleri, gayrimenkul finansman şirketleri finansal kiralama şirketleri, korumalı fonlar, para piyasası fonları, tüketici finans kurumları ve menkul kıymet şirketlerini görebiliriz.

Pozsar ve diğerleri 2010 yılında Federal Reserve Bank of New York için hazırladıkları raporda ise gölge bankacılığı dört temel alt başlığa ayırmışlardır; Devlet destekli gölge bankacılık (Freddie Mac, Funny Mae gibi), içsel gölge bankacılık, dışsal gölge bankacılık ve paralel bankacılık sistemi. (Pozsar, Adrian, Ashcraft, \& Boesky, 2010) Ancak bu noktada paralel bankacılık sisteminin dışsal gölge bankacılık sisteminin altında da incelenebileceğini belirtmekte fayda vardır. Dolayısıyla gölge bankacılık sisteminin üç temel alt başlık şeklinde de değerlendirilebileceğini söylemek mümkündür. Bu çalışmada tartışılan konu açısından bakıldığında konunun dışsal gölge bankacılık kapsamında değerlendirilmesi gerektiği düşünülmektedir. Bu bakış açısından hareketle gölge bankacılığın diğer temel alt başlıkları üzerinde durulmayacak çalışmanın amacı doğrultusunda bölümün geri kalanında dışsal gölge bankacılık sistemi üzerinde durulacaktır.

Dışsal gölge bankacılık faaliyetleri, genel olarak banka dışı bağımsız kurumlar tarafindan sunulan finansal hizmetler ve yönetilen gölge bankacılık aktiviteleri olarak tanımlanabilir. (Doruk, 2014) Dışsal gölge bankacılık sisteminde temelde bankacılık sistemi içerisinde olmayan ve bankacılık sisteminde var olan düzenlemelere tabi olmayan teşekküller tarafından gerçekleştirilen bankacılık faaliyetleri yer almaktadır. $\mathrm{Bu}$ teşekküller bankaların tabi olduğu bağımsız dış denetim, kurumsal yönetim ilkeleri gibi yasal düzenlemelere ve vergi yükümlülüklerine tabi olmadıkları için bankalar karşısında son derece önemli bir rekabet avantajına sahiptirler. Burada yeri gelmişken gölge bankacılık faaliyetlerinin bankacılık sisteminde var olan mevcut düzenleme ve denetimlere tabi olmadığını bir kez daha vurgulamak gerekir. (Gorton \& Metrick, 2010)

$\mathrm{Bu}$ sistemde gölge bankacılık kuruluşları, kısa vadeli borçlanıyor ve uzun vadeli likit olmayan varlıklara yatırım yapıyor. Müşterilerine; ipotekli krediler ve/veya varlığa dayalı ticari kâğıtlar karşılığında kredi verebiliyor. Özellikle ABD ve Avrupa'da oldukça yaygın olarak işlem yapan bu kuruluşlar arasında; yatırım bankaları, sigorta şirketleri, serbest yatırım fonları (hedge fon), yatırım fonları, devlet tarafından ipotekli 
konut kredisi vermeleri için desteklenen kurumlar sayllabilir. Türkiye'de ise bu kuruluşlara örnek olarak özellikle konut ve taşıt finansmanı için ürünler sunan şirketler verilebilir. Türkiye'de mevcut durumda gölge bankacılık teşekkülleri kanuni karşılığa ve vergi düzenlemelerine, ya da en azından bankacılık sistemindeki kadar yeterli ve sık1 düzenlemelere tabi olmadıkları için, Ticari bankalara göre daha düşük maliyetlerle finansman sağlayabilmektedir. Ancak bu noktada önemli bir hususun da gözden kaçırılmaması gerekir. $\mathrm{O}$ da denetim ve gözetim eksikliğinin yarattığı iflas veya yolsuzluk riski. Zira bankacılık sisteminde yapılan düzenlemelerin, denetim ve gözetim faaliyetlerinin ana amacı ortakların ve kamunun yolsuzluk ve iflas riskine karşı korunmasıdır. Yapılan bu gözetim faaliyetleri bankacılık sektörünün maliyetlerinin artmasına neden olmakla beraber bankacılık sektörünün güvenilir ve sağlam bir yapıya sahip olmasını sağlamaktadır.

$\mathrm{Bu}$ açıdan bakıldığında ve gölge bankacılığın dünyadaki durumu göz önünde bulundurulduğunda, bankaların mali yapılarının güçlendirilmesi ve etkin denetimi üzerine yoğunlaşan sıkı ve etkili düzenlemeler aynı zamanda gölge bankacılığın da gelişmesine katkıda bulunmuştur. Bu etki üç farklı açıdan ifade edilebilir;

1-Bankacılık faaliyetleri üzerindeki sıkı denetim ve gözetim faaliyetleri banka dışı kuruluşların bankacılık alanına giren hizmetler geliştirmesini ve sunmasını teşvik etmiştir,

2- Asgari Sermaye yeterliliği oranı gibi yükümlülükler, bankaların yatırımlarını ve faaliyetlerini düzenlemelerin olmadığı veyahut yetersiz olduğu bölgelere ve bilançoda gösterilmeyen bilanço dışı işlemlere kaydırmalarına neden olmuştur,

3-Düzenleme ve denetim bazı bölgelerde ve banka dışı finansal kuruluşlar üzerinde ya hiç yoktur ya da yetersizdir. Bu durum özellikle gölge bankacılık hizmeti veren kuruluşlara bankalar karşısında önemli bir rekabet avantajı sağlamaktadır. Ayrıca, gölge bankacılık sisteminin gelişimi hem kişiler hem de şirketler için finansal yatırım seçeneklerinin çoğaldığ 1 bir dönem ile de kesişir. Örneğin, Klasik banka müşterileri olan guruplar tercihlerini bankacılık sistemi dışındaki kuruluşlarda değerlendirmeyi tercih etmişlerdir. (Delikanlı, Alp, \& Kilic, 1997)

Gölge bankacılık sisteminin önemli araştırmacılarından birisi olan Gorton'a göre gölge bankacılık sisteminin oluşması en az 30-40 yıllık sürecin eseridir ve oluşma nedenleri (Doruk, 2014);

1-Bankacılık sektöründeki artan rekabet nedeniyle geleneksel bankacıllı̆gin daha az karlı hale gelmesi, 
2-Emeklilik fonları, yatırım fonları ve sigorta şirketlerinin fonlarını içeren piyasalarda kurumsal hızlı artışı,

3-Teminatlı borçların artması gölge bankacılık tarafından sağlanan yatırım imkânlarının daha güvenli hale gelmesine neden olmuştur. Bu da bankacılık sektörüne karşı elini güçlendirmiştir.

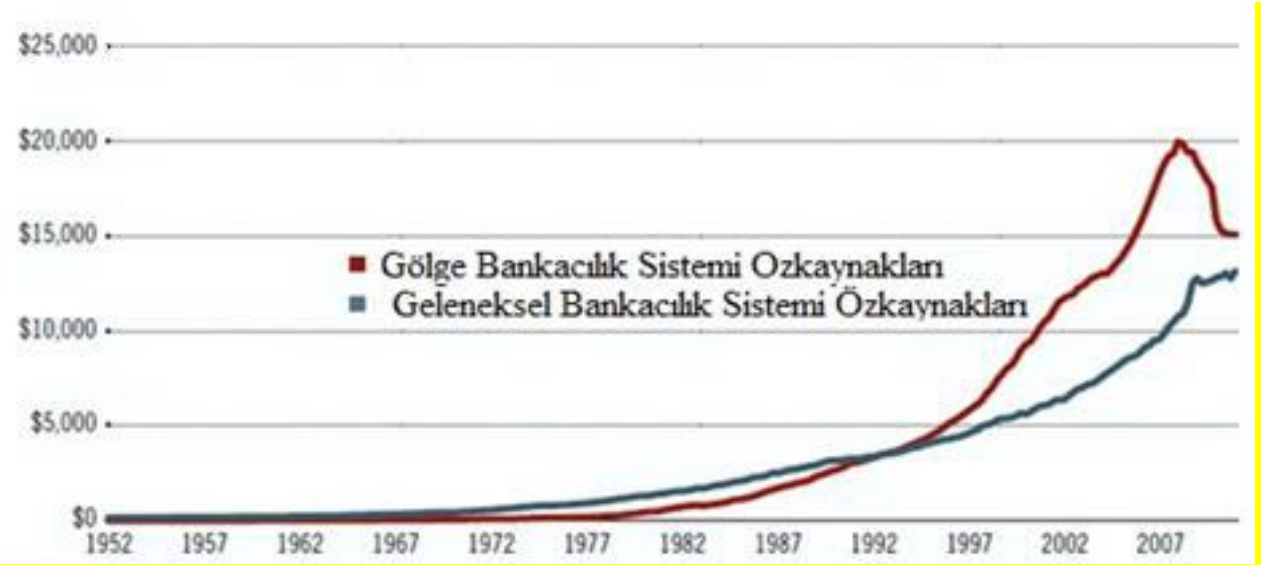

Grafik 1. Geleneksel Bankacılık Sistemi ve Gölge Bankacılık Sisteminin Gelişmesi(19522007,Milyar \$)

Geleneksek bankacılık sistemiyle gölge bankacılık sisteminin sağladıkları hizmetler, müşteriye kredi sağlama gibi paralellikler içerse de sermayelerini fonlama şekli açısından birbirlerinden ayrılmaktadır. Ayrıca geleneksel bankacılık sistemi hükümet tarafından düzenlendiği için bu durum işlem maliyetlerinin daha da artmasına sebep olmaktadır. Bir diğer taraftan gölge bankacılık sistemi hükümetten bağımsız hareket ettiği için bu tür maliyetler ortaya çıkmamaktadır. Gölge bankacılıktaki faiz oranları geleneksel bankalardan daha düşük olduğundan itibaren gölge bankacılığın büyüme oranları geleneksel bankacılığın önüne geçmiştir.

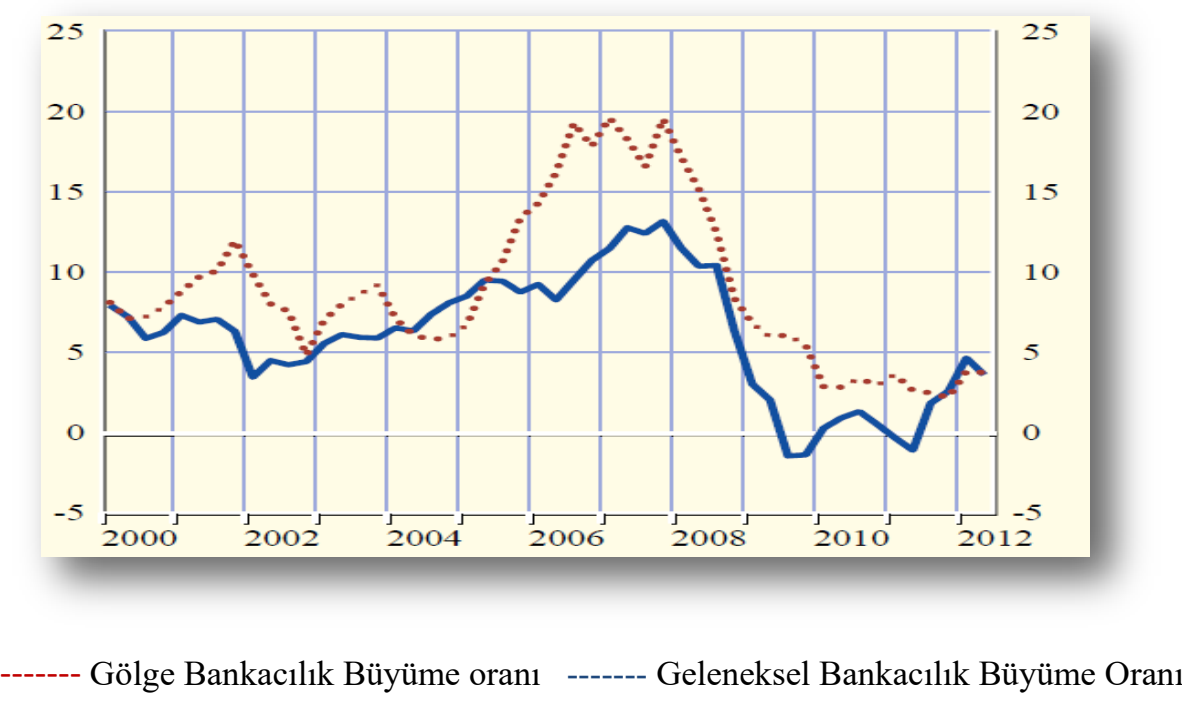


Grafik 2 Euro Bölgesindeki Bankalar Ve Diğer Kurumların Aktiflerinin Büyüme Oranı²

Yukarıda Avrupa Merkez Bankası'nın yayınladığı tabloya baktığımızda 20002012 yılları arasında gölge bankacılık sisteminin geleneksel bankacılık sistemine göre daha iyi bir büyüme oranının olduğunu görüyoruz. Özellikle 2002 yılında geleneksel bankacılık sisteminin büyüme oranı düşmesine rağmen gölge bankacılık sisteminin büyümesinde ciddi sıçrama yaşanmıştır. 2007'ye gelindiğinde ise dünya üzerindeki küresel finansal kriz ve oynaklığın artmasından dolayı hem bankacılık hem de gölge bankacılık sistemi büyük bir düşüş yaşamıştır. 2012'de ise her iki bankacılık sistemi de krizin etkilerinden kurtulmuş ve tekrar yukarı yönlü büyüme oranlarını yakalamaya başlamıştır.

Amerika'daki gölge bankacılık sistemine bakacak olursak Avrupa'ya göre neredeyse iki kat daha fazla toplam banka varlıkları bulunmaktadır. Avrupa'daki gölge bankacılık sisteminde Birleşik Krallık \%13, Hollanda \%8, Fransa \%6 ve Danimarka $\% 5^{\prime}$ lik oranlarla dünya gölge bankacılık sisteminin içinde yer almaktadır. ${ }^{3}$

Tablo 1: 2011'de Gölge Bankacılığın Değeri4

\begin{tabular}{|l|c|cc|}
\hline Ülke & USD trilyon & \% 2011 GSMH & \% Dünya Toplamı \\
\hline Amerika & 23 & $\% 152$ & $\% 35$ \\
\hline Euro Bölgesi & 22 & $\% 168$ & $\% 33$ \\
\hline Birleşik Krallık & 9 & $\% 370$ & $\% 13$ \\
\hline \hline Dünya Toplamı & $\mathbf{6 7}$ & $\mathbf{\% 1 1}$ & $\mathbf{\% 1 0}$ \\
\hline
\end{tabular}

Yukarıdaki tabloya baktığımızda 2011 yılında ülkelere göre gölge bankacılık sisteminin GSMH 'ye oranlarını görmekteyiz. Bu veriler Amerika' daki gölge bankacılık sisteminin toplam varlıklarının ülkedeki GSMH'nin 1.5 katından biraz daha fazla olduğunu göstermektedir. Söz konusu oranın Birleşik Krallıkta 3.7 katına kadar yükseldiği görülmektedir. Dünyadaki toplam gölge bankacılık varlıklarının ise toplam GSMH'nin 1.1 katı kadar olduğu görülmektedir. Tablo1'de sunulan veriler dünya çapında gölge bankacılık sisteminde dönen paraların büyüklüğünün hangi boyutlara ulaştığını gözler önüne sermektedir.

Özetlemek gerekirse gölge bankacılık sistemini geleneksel bankacıllk sisteminin tam olarak ikamesi gibi gözükmese de ona paralel bir sistem olarak değerlendirmek mümkündür. $\mathrm{Bu}$ sistemin gelişmesini sağlamak ve büyümeyi arttırmak piyasaya ve oyunculara olan faydalarının artmasına, risklerin ve işsizliğin hafifletilmesine ve finansman maliyetlerinin azalmasına olanak sağlayabilir. Fakat bu noktada dikkat edilmesi gereken çok önemli iki kilit nokta vardır. O da sıkı denetim ve şeffaflıktır. Bu sektörün denetimden uzak ve şeffaf olmayan bir yapıda gelişimi ileride finansal sistem ve ülke ekonomilerinde finansal krizlere kadar gidebilecek ciddi sorunlar yaşanmasına neden olabilir. Bir sonraki bölümde özellikle Türkiye ve Türkiye gibi gelişmekte olan ülkelerde gayrimenkul finansmanında kullanılabilecek bir yöntem ve bir gölge

\footnotetext{
${ }^{2}$ European Central Bank Enhancing the Monitoring of Shadow Banking 2013 Report. p. 93.

${ }^{3}$ EC. (2012). Green Paper-Shadow Banking: European Commission.p.4

4 (FED, 2013, p. 1)
} 
bankacılık uygulaması olarak İpoteğe Dayalı Paylaşımlı Faizsiz Finansman modeli üzerinde durulacaktır.

\section{Tasarrufa Dayalı Faizsiz Finansman Modeli / İpoteğe Dayalı Paylaşımlı Faizsiz Finansman Modeli (İP2FM)'ne Geçiş}

Modern ve sağlam bir konutta yaşamak veya yeni ve yüksek kaliteli bir otomobile binmek gibi bireysel ihtiyaçlar modern yaşamın en temel ihtiyaçlarındandır. Modern yaşamın bu tip ihtiyaçlarının karşılanması sorunu bilhassa gelişmekte olan ekonomilerde daha da önceliklidir. Bu açıdan bakıldığında hızlı gelişen ve nüfus artışı yaşayan ülkelerin bu konuda karşılaştıkları en önemli önemli engellerden bir tanesi de genelde tasarrufların yetersizliğinden kaynaklanan bireysel finansman konusudur. Konut finansmanı ise diğer bireysel finansman konuları arasında hem ekonomik gelişmedeki önemi hem de modernleşmenin temel göstergelerinden olması nedeniyle özellikle öne çıkmaktadır. Gelişmekte olan ülkelerde yaşanan güvenli ve yaşanılabilir konuta ulaşabilme probleminin temelinde ise finansmana ulaşmadaki zorluklar yatmaktadır. Dünya genelinde konut finansmanı bankalar, özel veya kamu konut finansman kuruluşları ve benzeri kuruluşlar tarafından sağlanmaktadır. Bu kuruluşlar tasarruf sahiplerinden veya finans piyasalarından topladıkları fonları konut finansmanı için fon ihtiyacı olanlara kullandırmaktadırlar.

Konvansiyonel finansman sistemleri tarafindan sağlanan fonların temeli faize dayanmaktadır. Bu durum özellikle bireysel tasarrufların ve sermaye birikiminin yetersiz, risk algısının yüksek olduğu gelişmekte olan ülkelerde finansman maliyetlerini aşırı yükseltmektedir. Sonuç olarak yüksek finansman maliyetleri finansmana ulaşımı zorlaştırmaktadır. Bu durum aşağıda yer alan grafikte açık bir şekilde görülmektedir. Grafik 3'te Kasım 2015-Aralık 2016 döneminde piyasada oluşan konut kredisi faizleri yer almaktadır.

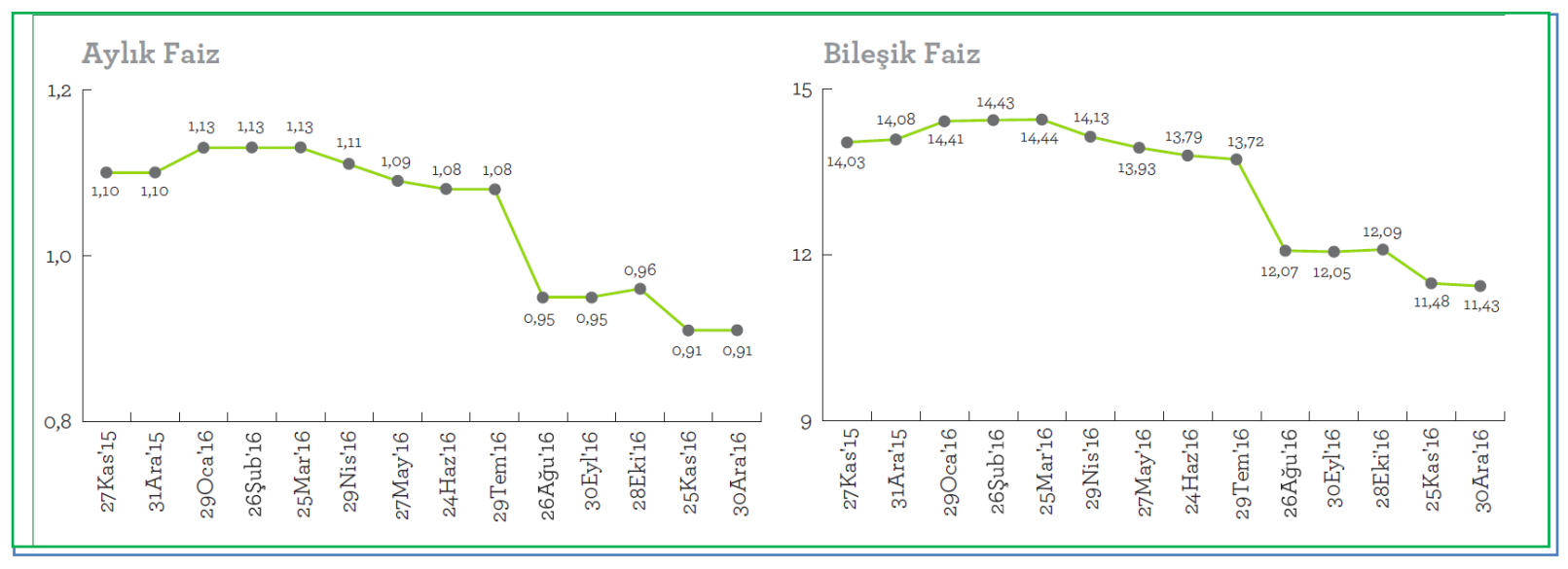

\section{Grafik 3. Konut Kredisi Maliyetleri (Faiz Oranları) ${ }^{5}$}

Konvansiyonel finans sisteminin alternatifi olarak ise faizsiz finansman kuruluşları yer almaktadır. Küresel bazda incelendiğinde faizsiz finans kuruluşların bireysel finansman konusunda faize dayanmayan çeşitli finansman yöntemleri geliştirdikleri görülmektedir. Bu finansman yöntemleri arasında mudaraba, murabaha, muşaraka, salam, icara (kiralama) gibi yöntemler sayılabilir. (Türker, 2010) Ancak

${ }^{5}$ GYODER Gösterge 2016 4.Çeyrek Raporu, www.gyoder.org.tr. 
Türkiye'de gerek uygulamadan kaynaklanan problemlerden gerekse alternatif yöntemlerin yetersizliğinden dolayı sunulan faizsiz finansman yöntemleri de bireysel finansmandaki potansiyel talebi karşılayacak ciddi bir alternatif yaratamamaktadır. $\mathrm{Bu}$ durum özellikle konut finansmanı talebinde daha da ciddi bir problem olarak öne çıkmaktadır. 2016 yılsonu itibarıyla Türkiye'de kullandırılan konut kredisi miktarı 175.901.000.000 TL'dir. Aynı dönemde 4 adet katılım bankası tarafindan kullandırılan konut kredisi miktarı ise 11.670.000.000 TL'dir. Katılım bankalarının kullandırdıkları konut kredilerinin toplam konut kredileri içindeki payı yalnızca \%7'dir. Aşağıda verilen Grafik 4'te bu durum açıkça görülmektedir.

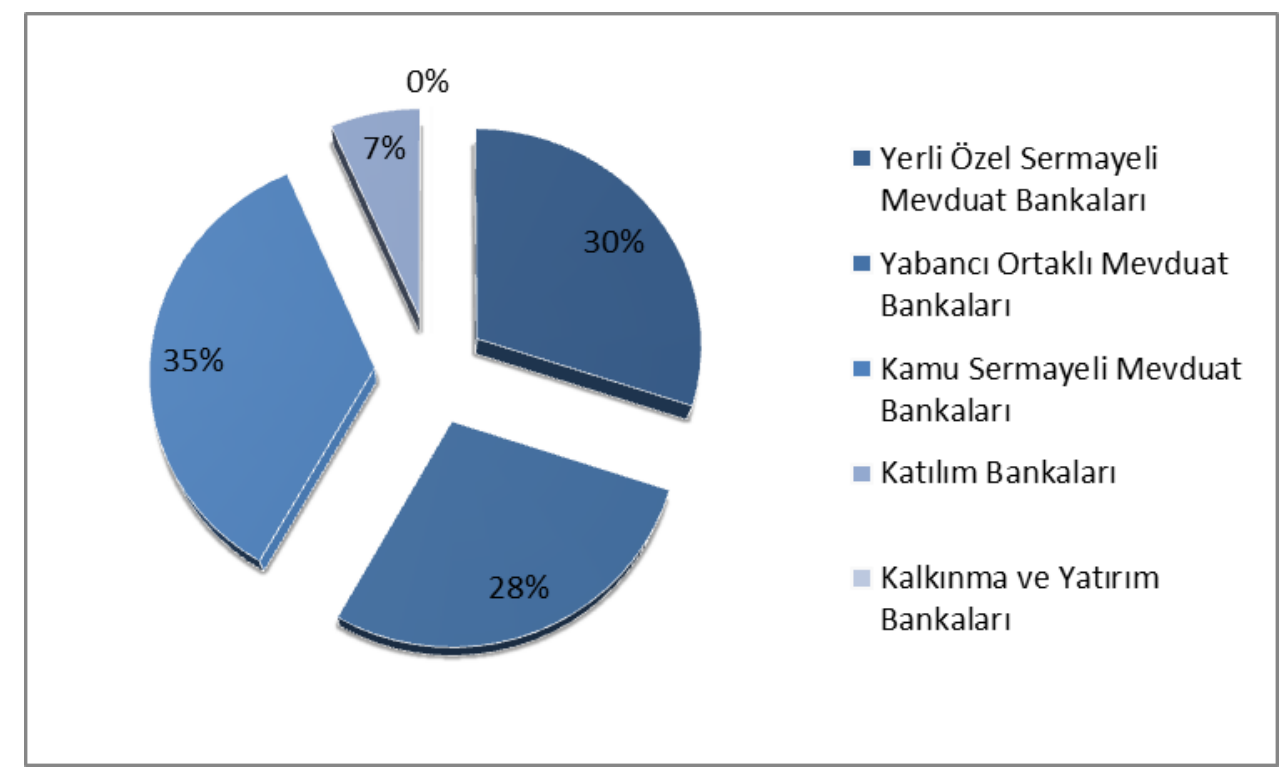

Grafik 4. Konut Kredisi Hacminin Bankalara Göre Dağılımı (\% olarak) ${ }^{6}$

Türkiye ekonomisine bakıldığında 2000'li yılların başından itibaren devamlı bir büyüme dönemi yaşandığı göze çarpmaktadır. Söz konusu dönemde hem dünyadaki gelişmelere paralel olarak hem de ülkede yaşanan değişimler sonucu faizsiz finansman ürünlerine ilginin arttığı söylenebilir. $\mathrm{Bu}$ ürünler arasında altın bankacılığı, kira sertifikaları, gayrimenkul sertifikaları ve tasarrufa dayalı faizsiz finansman ürünleri ilk akla gelenlerdendir.(Türker, 2010) Gayrimenkul finansmanı özelinde ise tasarrufa dayalı faizsiz finansman modeli bireysel finansman konusunda potansiyeli yüksek bir alternatif olarak öne çıkmaktadır. Bu yöntem Türkiye'de 1980'li yıllardan itibaren birkaç özel şirket tarafından faklı isimler kullanılarak uygulanmaktadır. Mevcut şirketler uyguladıkları sistemi katılımcıların finansman konusunda birbirlerine destek olduklarını vurgulamak açısından "elbirliği sistemi” olarak adlandırmaktadırlar. Bu ifade çok geniş bir kullanım alanı bulmamakla birlikte ilgili literatürdeki bazı kaynaklarda da geçmektedir. (Hacak, 2017; Kahraman, 2017; Tekerek, 2013) Konu ile ilgili bazı akademik kaynaklar ise uygulamada kullanılan yöntemi ifade etmek için Tasarrufa Dayalı Faizsiz Finansman Yönetimi'ni kullanmaktadırlar. (Kaya, 2017; Koç \& Çekin, 2017) Ancak sınırl literatürde kullanılan "tasarrufa dayal faizsiz finansman modeli kavramı" yöntemi tam olarak açıklayamamaktadır. Özellikle yöntemin uygulanması sürecinde en önemli aşamalarından olan ipotek edilme şartı gözden kaçmaktadır. Bu

${ }^{6}$ (GYODER, 2016) GYODER Gösterge 2016 4.Çeyrek Raporu, www.gyoder.org.tr. 
yüzden bu çalışmada modeli daha doğru ifade edeceği düşünülen "Ípoteğe Dayalı Paylaşımlı Faizsiz Finansman Modeli” (İP2FM) terimi geliştirilmiş ve de kullanılmıştır.

Çalışmanın bu bölümünün devamında gelişime potansiyeli yüksek bir alternatif bireysel finansman yöntemi olarak İpoteğe Dayalı Paylaşımlı Faizsiz Finansman Modeli (IIP2FM) üzerinde daha detaylı olarak durulacaktır. Bu model ile hem gayrimenkul hem de taşıt finansmanı sağlanabilmektedir. Konvansiyonel finansman sisteminden farklı olarak fon arz edenler yoktur, fon talep edenler oluşturdukları guruplar ile kendi finansmanlarını kendileri sağlamaktadırlar. $\mathrm{Bu}$ modelde yalnızca iki taraf vardır, finansman talep edenler ve aracılık eden kuruluş. Aracılık eden kuruluş gurupların oluşturulması, gurup üyeleri arasında koordinasyonunun sağlanması, üyeler tarafindan yapılan ödemelerin izlenmesi, yasal işlemlerin takip edilmesi gibi faaliyetleri gerçekleştirmektedir. (Tekerek, 2013) Aracılık eden kuruluşun temel işlevi gurubun organize edilmesi faaliyeti olarak tanımlanabilir. Finansman talep edenler, kuruluş tarafindan talep ettikleri finansman miktarı ve buna uygun belirlenen taksit tutarı ve vadeye göre guruplara ayrılmaktadır. Ayrıca katılımcılar peşinat tutarını da seçebilmektedir. Modelin işleyişi ise oldukça basittir. Gurup üyelerinin her ödeme dönemde ödediği taksitler ile biriken fon üyelerden birine verilir ve sistem bu şekilde devam eder. Bu Anadolu kültüründe var olan altın günlerine benzetilebilir. (Ergüven, 2014) Vadenin sonunda ise tüm üyeler talep ettikleri finansmanı sağlarlar, aracılık eden kuruluş da aracılık hizmet bedelini alır. $\mathrm{Bu}$ sayede İP2FM ile finansman süreci sonlanmış olur.

Günümüzde Türkiye'de İP2FM modelinin çeşitli varyasyonlarını çeşitli isimler adı altında uygulayan birkaç farklı şirket bulunmaktadır. Bu şirketlerin geçmişi 90'lı yılların başına kadar uzanmaktadır. Model ilk olarak bir otomobil finansman yöntemi olarak uygulanmaya başlamış daha sonra konut finansmanı içinde kullanılmaya başlanmıştır. Yaklaşık 25 yıllık bir uygulama geçmişine sahip olan model, aradan geçen sürede pek çok kişi tarafından kullanılmıştır. Ancak aradan geçen sürede model bir gölge bankacılık uygulaması olarak devam etmiş etkin ve yeterli düzeyde denetlenmemiştir.

\section{Bir Dışsal Gölge Bankacılık Uygulaması olarak İpoteğe Dayalı Paylaşımlı Faizsiz Finansman Modeli (İP2FM) ve Geleneksel Finansman Modelinin Genel Hatları ile Karşılaştırılması}

Finansal sistemi içerisindeki kuruluşlar tarafından sunulan finansman yöntemleri ile İpoteğe dayalı paylaşımlı faizsiz finansman modeli (IP2FM)'nin karşılaştırılması iki temel üzerinden yapılabilir. Buna göre;

İpoteğe dayalı paylaşımlı faizsiz finansman modeli (İP2FM) kendine has özellikleri ile geleneksel faizsiz finansman yöntemlerine göre bir alternatif bireysel finansman ürünü olarak karşımıza çıkmaktadır. Geleneksel finansmanda, finansman kuruluşu mudilerden topladığı mevduatlar ile oluşturduğu fonları tüketicilere kullandırmaktadır, bir tür aracılık hizmeti vermektedir. Fon arz eden taraf ile fon talep eden tarafin amaçları farklıdır. Bu durumda olarak fon arz eden haklı olarak bir getiri beklemektedir ve istenen getirinin maliyete eklenmesi gerekir. Dolayısıyla bu durum daha yüksek finansman maliyeti anlamına gelmektedir.

İpoteğe dayalı paylaşımlı faizsiz finansman modelinde (İP2FM) ise fon talep eden gurup fon arz eden gurubu oluşturmaktadır. Yani fon arz edenler ile fon talep edenler aynı kişilerdir dolayısıyla iki gurup arasında amaç birliği söz konusudur. Fon 
talep edenler ile fon arz edenler aynı kişiler oldukları için finansman ihtiyacı dışında bir getiri beklentileri yoktur. Geleneksel yöntemde ise fon arz edenler ile fon talep edenlerin amaçları farklıdır. Burada bilhassa fon arz edelerin amacı finansman maliyetini arttırmaktadır. Fon arz edenler fonlarını bir getiri beklentisi ile arz etmektedir. Fon arz edenlerin istedikleri reel getiri miktarı finansman maliyetinin temelini oluşturmaktadır.

Geleneksel finans sisteminde riskin maliyeti fon talep eden tarafindan üstlenilmektedir. Üstlendiği risk karşıllı̆ında fon talep eden risk primini fon arz edene ödemektedir. İpoteğe dayalı paylaşımlı faizsiz finansman modelinde (İP2FM) ise risk taraflar arasında paylaşılmaktadır. Bu gayet normal bir durumdur. Zira modelde fon arz edenler ile fon talep edenler aynı kişiler olduğu için mevcut risk taraflardan biri tarafından diğerinin üzerine yüklenmemektedir.

Ayrıca mevcut risk de guruptakiler arasında eşit olarak paylaşılmış, dolayısıyla risk primi azalmıştır. Bu durumda hem getiri beklentisinin olmaması hem de risk priminin taraflar arasında paylaşılmış olmasından dolayı finansman maliyetini geleneksel yönteme göre oldukça avantajlı hale getirmektedir.

Yukarıda bahsedilen temel hususlar dikkate alındığında ipoteğe dayalı paylaşımlı faizsiz finansman modeli (IP2FM)'nin ya da farklı isimlerle de ifade edilen bu modelin aslında finans kuruluşlarının kredi fonksiyonu çerçevesinde değerlendirmesi gerektiği görülmektedir. Zira oluşturulan gurup sayesinde bir fon sağlanmakta ve bu fon sırasıyla gurup üyelerine kullandırılmaktadır. Gurubun vadesi içerisinde fonların kontrolü ve yönetimi aracılık eden kuruluş tarafindan yapılmaktadır. Dolayısıyla İP2FM'nin bir dışsal gölge bankacılık uygulaması olduğunu söylemek mümkündür.

\section{Sonuç ve Öneriler}

İpoteğe dayalı paylaşımlı faizsiz finansman modeli (İP2FM) farklı terminolojiler kullanılarak birkaç şirket tarafindan Türkiye'de 1990'lı yılların başından itibaren uygulanmaktadır. IP2FM temel olarak bakıldığında taşıt ve gayrimenkul finansmanında kullanılan, faiz içermeyen bir bireysel finansman yöntemidir. Aynı amaca sahip bireylerin bir aracı kuruluş tarafından bir araya getirilmesi ile yaratılan sinerji ile finansman ihtiyacının karşılanması temeline dayanır. Bir önceki bölümde ifade edildiği üzere söz konusu süreç ana hatlarıyla bakıldığında bankacılığın kredi fonksiyonu çerçevesinde değerlendirilebilir. Ancak İP2FM kapsamındaki şirketler bankacılık sistemi için geçerli olan denetim ve düzenlemelerin dışında kaldığı için IP2FM'nin mevcut haliyle bir gölge bankacılık örneği olduğunu söylemek mümkündür. $\mathrm{Bu}$ noktadan hareketle aşağıda yer verilen hususlar büyük önem taşımaktadır.

- Finansal sistemin sağlıklı ve düzgün işleyişi finans sektörünün ve ekonominin gelişimi açısından son derece kritiktir. Finansal sistemin oyuncularının yaşayacağı problemler ekonominin geneli için ciddi risk oluşturur. İP2FM ile sunulan hizmet finans sektörünün kapsamında değerlendirilmelidir. Dolayısıyla İPFM'yi uygulayan kuruluşlar kamu otoritesi tarafindan aynen finans sektörünün diğer kurumlarında ve özellikle de bankacılık kesiminde olduğu gibi ciddi bir denetim ve gözetim altına alınmalıdır. Kanun koyucu tarafindan özellikle lisanslama ve denetim alanındaki yasal düzenlemeler en kısa sürede yapılmalıdır. Zira son yıllarda yaşanan büyüme ile kayda değer bir büyüklüğe ulaşan söz konusu kuruluşlar gerekli düzenlemelerin yapılmaması durumunda 
ülke ekonomisinde finansal kriz boyutuna kadar gidebilecek ciddi sorunların yaşanmasına neden olabilir. (D'Arista \& Schlesinger, 1993)

- Organizatör kuruluşlar, aracılık hizmetlerinin yanında aslında fon toplama ve fon kullandırma ve yönetimi hizmeti de verdikleri için bir an önce gerekli yasal düzenlemeler yapılarak finansal kurum olarak kabul edilmeli ve en kısa zamanda ilgili düzenleyici üst kurumlar tarafından denetim ve gözetim altına alınmalıdır.

- İP2FM'nin mevcut uygulamalarında sunulan ürünlerde ve finansman koşullarında bir standardizasyon sağlanamamıştır. (Katılımcılardan kira yardımı adı altında alınan miktarın standardizasyonu veya sözleşme koşullarının ne olacağ1 gibi) (Koç \& Çekin, 2017) Bu konuda düzenleme yapılarak sunulan ürün ve koşullarda bir standardizasyonun sağlanması gerekmektedir.

- İP2FM kapsamındaki şirketlerde oluşan serbest fonların hangi yatırım hangi alanlarda ve hangi araçlara ne şartlarda kullanılabileceği konusunun düzenlenmesi gerekmektedir.

- IPPFM'nin şimdiye kadarki uygulaması geleneksel ve sıkı bir şekilde denetlenen finans sektörü dışında kalan özel şirketler tarafından yürütülmektedir. Ancak hala sunulan ürünlerde ve şartlarda bir standardizasyon sağlanamamıştır. İP2FM'nin hem kamu hem de özel sermayeli katılım bankaları tarafindan geliştirilerek ve standardizasyonu sağlanarak uygulanması halinde özellikle faizsiz gayrimenkul finansmanında ciddi bir alternatif haline gelebilir. $\mathrm{Bu}$ aşamada kamunun oynayacağı öncü rol kritik bir öneme sahiptir.

- $\mathrm{Bu}$ modelin geliştirilmesinde, şeffaflaştırılmasında ve denetlenebilir hale getirilmesine kamu sermayeli katılım bankaları ya da sadece gayrimenkul finansmanı üzerinde uzmanlaşacak bir finansal kurum kullanılabilir. Bu sayede mevcut uygulamadan kaynaklanan potansiyel riskin yönetilebilir hale gelmesi ve güvenin artması sağlanabilir.

- Mevcut durumda İP2FM'nin benzer versiyonlarını uygulayan aracı kuruluşlar finans sektöründeki düzenlemelerin ve sıkı denetimlerin kapsamı dişında kaldıkları için finans sektöründe faaliyet gösteren ve benzer hizmetleri veren kurumlar karşısında ciddi bir maliyet avantajına sahiptirler. $\mathrm{Bu}$ durum ise sektörde haksız rekabete neden olmaktadır.

Sonuç olarak yukarıda ifade edilen önerilerin gerçekleştirilmesi halinde İPFM'nin Türkiye'de yaşanan gayrimenkul finansman ihtiyacının karşılanmasında önemli bir katkı sağlayabileceği düşünülmektedir. Bu model özellikle orta ve düşük gelir gurubunun gayrimenkul ihtiyacının finansmanında ciddi bir alternatif yaratabilir. Ancak IP2FM'nin geliştirilmesi ve standart hale getirilmesi önemlidir. Bu süreçte kamunun hem düzenleyici otorite hem de uygulamacı olarak kamu sermayeli katılım bankaları üzerinden katılımı sürecin sağlıklı işlemesini sağlayacaktır. Özel sermayeli katılım bankalarının da alternatif bir ürün olarak İP2FM'yi kullanmaları hem daha geniş kitlelere ulaşımı sağlayacaktır hem de sistemin güvenilirliğini arttıracaktır. Ayrıca faizsiz finansman imkânı sağlaması da faiz hassasiyeti olan kesimler açısından önemlidir. Son dönemde yaşanan gelişmeler ulusal ve uluslararası düzeyde faizsiz araçlara ilgiyi arttırmıştır. Siyasi iradenin de faizsiz finansmanın gelişimini destekleyen yönde bir tasarrufu bulunmaktadır. Faizsiz finansmanda ürün çeşitliliğinin artması ve alternatif ürünlerin çoğalması talebin artmasını ve finans sektörünün de gelişmesine katkı sağlayacaktır. 
Bundan sonraki dönemde İP2FM modelinin geliştirilmesi ve standart hale getirilmesi ve ayrıca kamu tarafından denetim ve gözetim ve düzenlemelerin ne şekilde olması üzerine yapılacak çalışmaların gerek faizsiz finansman sektörüne ve gerekse de literatürüne kayda değer katkı sağlayacağı değerlendirilmektedir.

\section{Kaynakça}

Berberoğlu, M. G. (2005). Konut finansmanı ve Türkiye'ye uygun bir model önerisi. İstanbul Teknik Üniversitesi,

Board, F. S., \& Basel, S. (2015). Shadow banking monitoring report. In: Basel: Financial Stability Board.

Claessens, S., \& Ratnovski, L. (2015). What is shadow banking?

D'Arista, J. W., \& Schlesinger, T. (1993). The parallel banking system: Economic Policy Institute.

Delikanlı, İ. U., Alp, A., \& Kilic, S. (1997). Shadow Banking for Connected Lending and The Countermeasures: Turkish Case. Quarterly Economics and Finance Review, 12(48), 31.

Doruk, O. T. (2014). Gölge bankacılık ve Türkiye: Türkiye Bankalar Birliği.

Ergüven, M. (2014). Konut finansmanında elbirliği sistemi: Müşterilerin elbirliği sistemi tercihleri üzerine bir araştırma. Türk Hava Kurumu Üniversitesi

Gorton, G., \& Metrick, A. (2010). Regulating the shadow banking system. Brookings papers on economic activity, 2010(2), 261-297.

GYODER. (2016). GYODER Gösterge, Türkiye GayriMenkul Sektörü 4.Çeyrek. Retrieved from

Hacak, H. (2017). Tasarrufa Dayalı Faizsiz Finansman Sisteminde Yapılan Akitlerin Analizi (Elbirliği Finansman Sistemi Üzerinden). In H. M. Günay, Ş. Görmüş, İ. Koç, \& Ö. Çekin (Eds.), Tasarrufa Dayalı Faizsiz Finansman Sistemi (pp. 122). İstanbul: Ensar Neşriyat.

Kahraman, A. (2017). Bir Faizsiz Finansman Yöntemi Olarak Müşâreke Akdi ve Tasarrufa Dayalı Faizsiz Sistem (Elbirliği Sistemi Örneği). In. H. M. Günay, Ş. Görmüş, İ. Koç, \& Ö. Çekin (Series Eds.), Tasarrufa Dayalı Faizsiz Finansman Sistemi (pp. 122): Ensar Neşriyat.

Kaya, S. (2017). Faizsiz Finans İlkeleri ve Tasarrufa Dayalı

Faizsiz Finansman Sistemine Dair Öneriler. In H. M. Günay, Ş. Görmüş, İ. Koç, \& Ö. Çekin (Eds.), Tasarrufa Dayalı Faizsiz Finansman Sistemi (pp. 122). İstanbul: Ensar Neşriyat.

Koç, İ., \& Çekin, Ö. (2017). Tasarrufa Dayalı Faizsiz Finansman Sistemi: İşleyiş, Değerlendirme ve Tasarım

In H. M. Günay, Ş. Görmüş, İ. Koç, \& Ö. Çekin (Eds.), Tasarrufa Dayalı Finans Sistemi. İstanbul: Ensar Neşriyat Tic. A.Ş. 
Kodres, L. E. (2013). What is shadow banking. Finance and Development, 50(2), 4243.

Kömürlü, R. (2006). Ülkemizde toplu konut üretimine yönelik kaynak oluşturma model yaklaşımları. Yıldız Teknik Üniversitesi

Pozsar, Z., Adrian, T., Ashcraft, A. B., \& Boesky, H. (2010). Shadow banking.

SERPAM, S. P. A. v. U. M. (2013). İslamî Finans-İslamî Finans Kavramı, Ürünler, Dünyada veTürkiye'de Gelişimi ve Geleceği Retrieved from İstanbul:

Tekerek, S. (2013). Konut finansmanında banka kredilerine alternatif modellerden Elbirliği sistemi üzerinde bir çalışma / Konut finansmaninda banka kredilerine alternatif modellerden Elbirliği sistemi üzerinde bir çalişma. Gazi Üniversitesi

Türker, H. (2010). İslami Finans Sisteminde Finansal Aracılık: Dünyadaki Gelişmler ve Sermaye Piyasasının Geliştirilmesi Açısından Türkiye için Öneriler. Retrieved from http://www.spk.gov.tr/SiteApps/Yayin/YayinGoster/1021.

https://www.eminevim.com/ , 25.07.2017

http://fuzulev.com/ ,25.07.2017

http://www.birevim.com/ , 05.08.2017 


\section{An Alternative Non-Interest Real Estate Financing Model as a Shadow Banking Practice: Mortgage-backed Non-interest Shared Finance Model}

\author{
Mustafa OKUR \\ Marmara University \\ School of Banking and Insurance \\ İstanbul, Turkey \\ orcid.org/0000-0003-3121-8603 \\ mustafaokur@marmara.edu.tr
}

\author{
Özgür ÇATIKKAŞ \\ Marmara University \\ School of Banking and Insurance \\ İstanbul, Turkey \\ orcid.org/0000-0001-9547-8741 \\ ozgurcatikkas@marmara.edu.tr
}

\author{
Mehmet ERSOY \\ Marmara University \\ School of Banking and Insurance \\ İstanbul, Turkey \\ orcid.org/0000-0003-4057-6752 \\ mersoy@marmara.edu.tr
}

\section{Extensive Summary}

Housing finance is crucial for the sustainable growth of the country's economy. This issue is of even greater importance for emerging economies such as Turkey. When we look at the applications in the world in terms of housing finance, it is seen that housing finance is provided by non-bank institutions such as private or public housing finance institutions besides banks. These types of organizations offer alternative products to their customers and finance the purchased houses. In general, however, the basis for housing finance products produced and offered by the conventional financial system is based on interest. This situation raises housing finance costs, especially in developing countries, where funds are insufficient and risk perception is high. In addition, some groups, especially Muslims, do not prefer interest-based housing financing methods. Therefore, interest-based methods are an obstacle for sustainable development of the housing finance problem for developing economies. In addition, some groups, especially Muslims, do not prefer interest-based housing financing methods.

As an alternative to the interest-based conventional system, non-interest financing institutions and their interest-free products can be evaluated. Such organizations use mudarabah, musarakah and etc. as an alternative to interest-based instruments for housing finance. However, due to some problems experienced in practice non-interest financing system cannot create a serious alternative to meet the needs of the existing housing finance problem in Turkey. Some of these problems include problems of practice in practice, lack of knowledge in the community and lack of alternative products offered. 
Mortgage-backed Non-interest Shared Finance Model (IP2FM) is a serious alternative to increasing the individual savings and the individual finance. In the implementation of this method, the participants are organized in groups, mostly by the organizer and financing is provided for housing purchases. This model, which has different variations in practice, could be seen as an alternative method of housing finance. Generally, this model is applied by companies that we can identify as an organizer company. As far as current practices are concerned, the ongoing situation can be regarded as a shadow banking practice as the organizer firms are not subject to finance sector regulations. However, in order to implement this system in a way that is healthy and sustainable and as a good example of practice to the world, and to solve the problem of housing finance, it is necessary to establish a complete legal infrastructure especially in order to prevent its possible negative effects for the public interest.

In this part, the Mortgage-backed Non-interest Shared Finance Model (IP2FM) will be discussed in more detail as an alternative method of individual financing. With this model, both real estate and vehicle financing can be provided. Unlike the conventional financing system, there are no need for external funds, and those who demand funds provide their own financing with the groups they create. There are only two parties in this model, those who demand need funds and the organizing institution as an intermediary party. It carries out activities such as the establishment of selffunding groups, ensuring coordination among the members, monitoring the payments made by the members, and monitoring the legal proceedings. The main function of the organizing institution can be defined as the organization of the self-funding group. That fund demanding individuals are organized into groups according to the amount of funds requested by each individual, and the amount of installments determined accordingly. Participants can also select the down payment amount. The operation of the model is quite simple. With the installments paid by the members of the group in each payment period, the accumulated fund is given to one of the members to fulfill his funding needs, and the system continues in this way. This can be compared to the golden days that exist in Anatolian culture. At the end of the maturity, all members receive the funds they needed, and the intermediary institution receives the organization fee. Finally, the financing process with IP2FM is completed.

As a result this model is expected to provide a significant contribution in meeting the funding needs of the real estate. IP2FM experienced in Turkey's case the realization of the recommendations expressed above. This model can create a serious alternative to the financing of real estate needs especially of the middle and low-income groups. However, it is important to develop and standardize the IP2FM. In this process, the participation of the public through both state-owned participation banks as an implementer and as a regulator will ensure the healthy functioning of the process. Also the use of IP2FM as an alternative product for private banks' participation banks will make them reach a larger group of consumers and increase the reliability of the system. Interest-free financing is also important in terms of interest-sensitive segments. Recent 
developments in the global finance system have increased interest in interest-free instruments at national and international levels. Political will also have a saving in the direction of supporting the development of interest-free financing. Increasing product scale and increasing the number of alternative products in interest-free financing will increase the consumer demand and contribute to the development of the finance sector. 